\title{
Performance Advantages of Labyrinth Weir
}

\author{
T.R. Neelakantan, D. Vijay, R. Sasikrishna, R. Ashokkumar
}

\begin{abstract}
Weir is a very common structure across water courses to control flow and to release surplus water from water bodies. Simple straight weirs are less efficient compared to labyrinth weir where the weir length is increased by folds. In this research, experiments were conducted in the laboratory to find the increase in discharge due to labyrinth or decrease in coefficient of discharge due to labyrinth. Further two labyrinth weirs were analyzed to understand the efficiency with respect to the shape of the labyrinth weir. Compared to the ogee weir, the labyrinth weir discharges more water (more than 60\%) for the same head of flow.
\end{abstract}

Keywords : coefficient of discharge, hydraulic performance, labyrinth weir, ogee weir

\section{INTRODUCTION}

$\mathrm{T}$ hough labyrinth means a complicated maze like structure, the labyrinth weir is not so complicated. Labyrinth weir increases the weir length over which water overflow. The labyrinth form is achieved by folding the straight length of the conventional weir into shapes as shown in Fig. 1. Increased weir length by folds, gives an exciting solution to increase discharges over the weir within the width of same stream or river. The width of the channel is not changed; but the weir length across the channel is increased. The top view of the labyrinth weirs in triangular, rectangular, trapezoidal and arc forms are shown in Fig. 1.
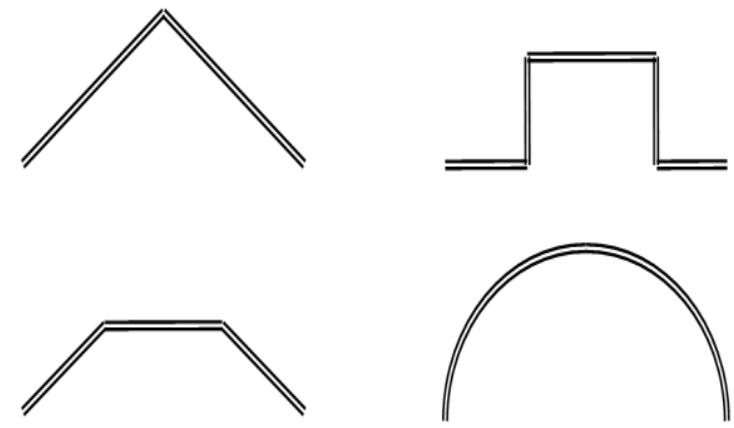

Fig. 1. Top-view of labyrinth weirs of various forms

Revised Manuscript Received on December 30, 2019.

* Correspondence Author

T.R. Neelakantan*, Department of Civil Engineering, Kalasalingam Academy of Research and Education, Krishnankoil 626126, India, neelakantan@klu.ac.in

D. Vijay, Department of Civil Engineering, Kalasalingam Academy of Research and Education, Krishnankoil 626126, India, dvijay0506097@gmail.com

R. Sasikrishna, Department of Civil Engineering, Kalasalingam Academy of Research and Education, Krishnankoil 626126, India, sasik1997@gmail.com

R. Ashokkumar, Department of Civil Engineering, Kalasalingam Academy of Research and Education, Krishnankoil 626126, India, askokraja081996@gmail.com
During the flood condition, discharge from a reservoir is crucial as a lower discharge may result in dam break. Dam breaks often result in economic and life losses in the downstream. Hence, to improve safety from dam break, increasing the discharge capacity of weir or spillway was researched. Different geometries to increase the length of the weir, and/or to increase the head causing flow were researched. One of the promising designs of weir or spillway is the labyrinth spillway. Global warming and related climate vagaries results in heavy downpour of rainfall and hence the discharges in channels and rivers are reaches higher maximum floods. The safe design discharges may not be satisfactory due to the changed situations and in such a situation, the labyrinth weir in place of simple straight weir will be of great use. Further, during the construction of new weirs, the labyrinth can be considered. A labyrinth form, increasing the effective weir length, gives an exciting solution to increase discharges by maintaining the width of conventional weirs. A labyrinth weir is a linear weir folded in plan-view; this structural form presents several advantages when compared to linear weir structures.

The flow over a rectangûar $Q_{t}=\frac{1}{3} b \sqrt{2} H^{\text {ir }}$ expressed as follows.

In the above equation, $Q_{t}$ is theoretical discharge, $b$ is length of weir, $H$ is head causing flow or head over the weir, and $g$ is acceleration due to gravity. To find the actual discharge, a discharge coefficient $C_{d}$ (value less than 1) is multiplied with $Q_{t}$.

$$
Q_{a}=C_{d} \frac{2}{3} b \sqrt{2 g} H^{3 / 2}
$$

In the labyrinth weir, the value of $b$ is increased by folding and hence a larger discharge is expected for the same value of $H$. However, discharge is not linear function of $b$. Due to the inclined nature of weir with respect to the flow direction, the $C_{d}$ value differs significantly and the increase in discharge is nonlinear function of $b$. The relationship between $b$ and $C_{d}$ value is a research question attempted by many. The shape of the labyrinth, angle of inclination and many factors affect the relationship between $b$ and $C_{d}$ value. In this study, another attempt is made in this direction. Two variations of labyrinth weirs of same $b$ value but different shapes are tested and $C_{d}$ values are estimated. The objectives of this research are to estimate the percentage increase in discharge due a labyrinth setup and to compare a weir labyrinth model placed in flipped position. 


\section{Performance Advantages of Labyrinth Weir}

\section{LABYRINTH WEIR}

Significant amount of research have been conducted and data were published on labyrinth weirs. Design curves were developed for the design of labyrinth weirs from 1970s [1]-[3]. Some of the researches used real size labyrinth weirs such as Avon Spillway [2], Brazos Spillway [4], Ute Dam [5], Hyrum Dam [6], Standley Lake [7], Weatherford Reservoir [8] where physical models were used to design prototype labyrinth weirs. Even after these studies, the need for more rigorous research is felt as the design procedures are yet to be standardized.

Hydraulic experts prefer to utilize and maximize the advantages of Labyrinth weirs. Increased crest length provided by a labyrinth weir renders higher discharge capacity for a given head causing head. Labyrinth weirs are also useful for higher aeration and better energy dissipation. Though many geometric designs are possible for labyrinth weirs, triangular, and trapezoidal labyrinth cycles are popular. Mathematical modeling of the flow of water over a labyrinth weir is complicated as a three-dimensional numerical modeling with the conservation of energy, momentum, and continuity, and the effects of viscosity, geometry, scale are crucial. Hence, researchers resort to experiments with physical models to find empirical coefficients. Many labyrinth parameters such as Headwater Ratio, Cycle Width Ratio, Relative Thickness Ratio, Cycle Efficiency [9], [10] were studied earlier; however, being experimental studies more generalizations will help the design engineers.

\section{EXPERIMENTAL SETUP}

Tilting flume available at Department of Civil Engineering, Kalasalingam Academy of Research and Education, was used in this study. It has a length of $2.5 \mathrm{~m}$, width of $0.25 \mathrm{~m}$, and height of $0.3 \mathrm{~m}$. The water supply to the flume is a closed circuit arrangement with a pump. To ensure uniform flow in the flume, water was supplied into the flume through a stilling chamber. The flume body is made of transparent perspex material for easy observation of flow. The weir models were made of wood and painted for a smooth surface. The lengths of the models were made exactly equal to the width of the flume $(0.25 \mathrm{~m})$ so as to fit exactly in the flume. A hook gauge was used to measure the water level in the flume. The actual discharge from the flume was measured from the volume of water collected in a collection tank provided at the outlet of the flume and the time required for the collection.

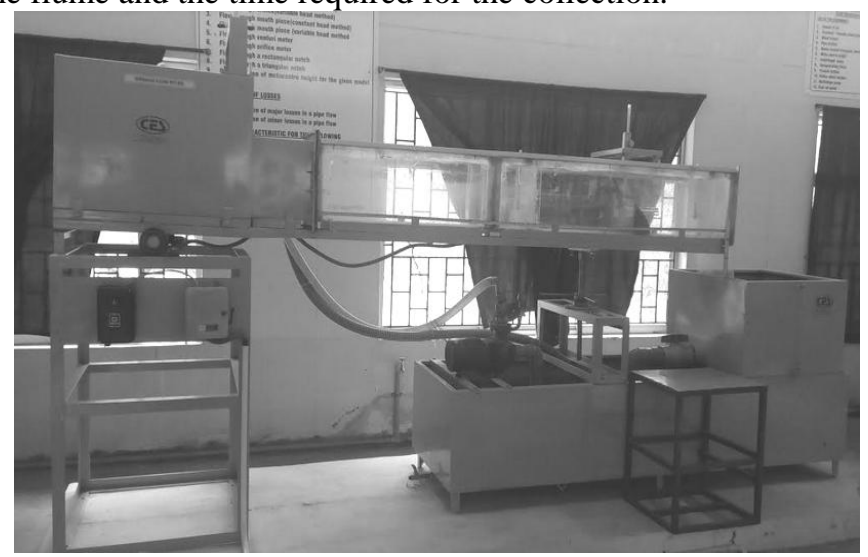

Fig. 2. Tilting Flume

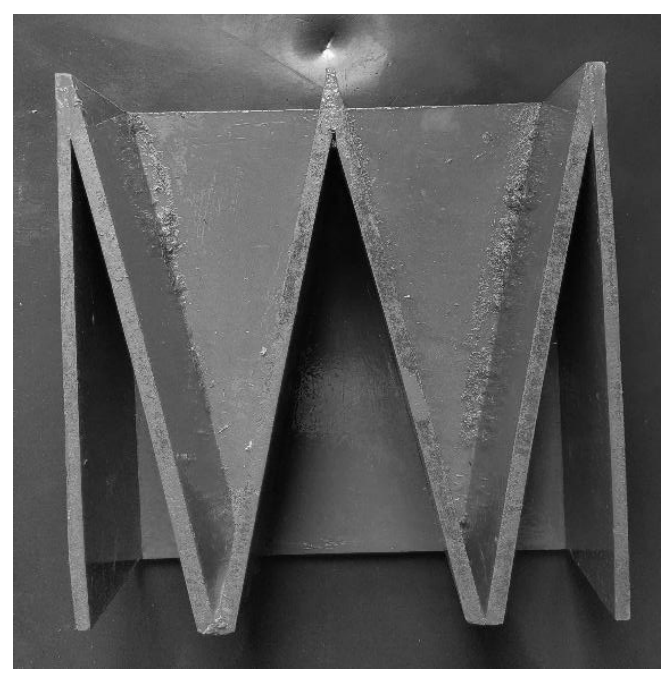

Fig. 3. Labyrinth Weir

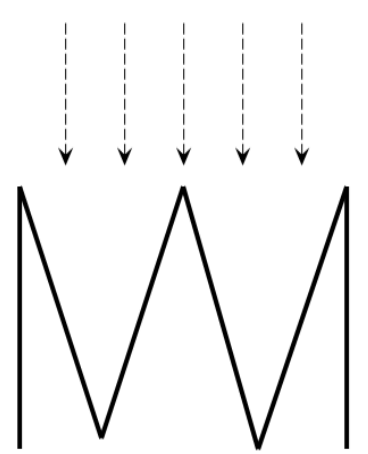

$\mathrm{W} \downarrow$ model

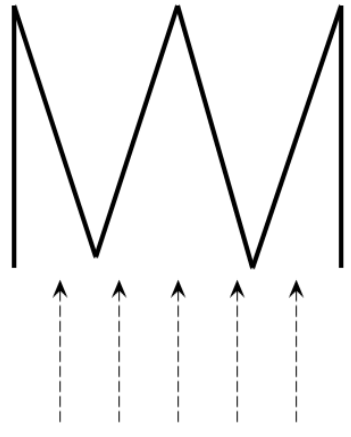

$\mathrm{W} \uparrow$ model
Fig. 4. Labyrinth weir orientations to flow direction

An ogee weir and a labyrinth weir were used in the experiments. A single labyrinth model of the shape $\mathrm{W}$ was used for two set of measurements by flipping the upstream and downstream sides as shown in Fig. 4. To differentiate the two sets, $\mathrm{W} \downarrow$ and $\mathrm{W} \uparrow$ notations were used in which the arrow indicates the flow direction. In the first case $\mathrm{W} \downarrow$, water flows into two triangular wedges before it flows over the weir as shown in Fig. 4. In the second case $\mathrm{W} \uparrow$, water flows into a single central wedge and two half-wedges near the boundaries before crossing the weir as shown in Fig. 4 Even though geometrical addition of both sets provides the same, the second set is expected to experience slightly more frictional resistance as the boundary wedge widths are relatively smaller. Flow over labyrinth weirs were compared with that of ogee weir. The coefficient of discharge $C_{d}$ is calculated by the ratio $Q_{a} / Q_{t}$. In this study, for the labyrinth weir, the total length of the weir through the folds is used as $b$ and the $C_{d}$ value of labyrinth weir was estimated and compared with the $C_{d}$ value of ogee weir. The value of $b$ is taken as $0.25 \mathrm{~m}$ and $1.24 \mathrm{~m}$ respectively for the ogee and labyrinth weirs. 


\section{RESULTS AND DISCUSSION}

The experimental results of ogee weir are presented in Fig. 5. The velocity of flow ranged between $0.015 \mathrm{~m} / \mathrm{s}$ to 0.072 $\mathrm{m} / \mathrm{s}$ and the Froude number range was from 0.012 to 0.054 . Labyrinth experiments for $\mathrm{W} \downarrow$ weir setup, velocity range was $0.05 \mathrm{~m} / \mathrm{s}$ to $0.223 \mathrm{~m} / \mathrm{s}$ and the Froude number range was 0.053 and 0.214 . Labyrinth experiments for $\mathrm{W} \uparrow$ weir setup, velocity range was $0.048 \mathrm{~m} / \mathrm{s}$ to $0.198 \mathrm{~m} / \mathrm{s}$ and the Froude number range was 0.052 and 0.191 .

The coefficient of discharge for ogee weir is found as 0.789 (Fig. 5). For $\mathrm{W} \downarrow$ model coefficient of discharge is estimated as 0.307 (table 1) and for and for $\mathrm{W} \uparrow$ model coefficient of discharge is estimated as 0.299 (table 1). Compared to $\mathrm{W} \downarrow$ model, the $\mathrm{W} \uparrow$ model has higher boundary effects as the flow paths are narrower in the wedges at the boundaries of the flume. Hence, the it is expected that the friction can be slightly more in $\mathrm{W} \uparrow$ model. Hence, a slightly lower flow is in the $\mathrm{W} \uparrow$ model is expected and the same is refelected in the experimental data. A considerable fall is seen in $C_{d}$ value in the case of labyrinth weirs compared to the ogee weir. However, for a same upstream head, labyrinth weirs could discharge more compared to the ogee weir. The percent increase in discharge estimated by $100 \times\left(Q_{\text {Labyrnth }}-Q_{\text {Ogee }}\right) / Q_{\text {Ogee }}$ for various discharge causing heads are presented in table 2.

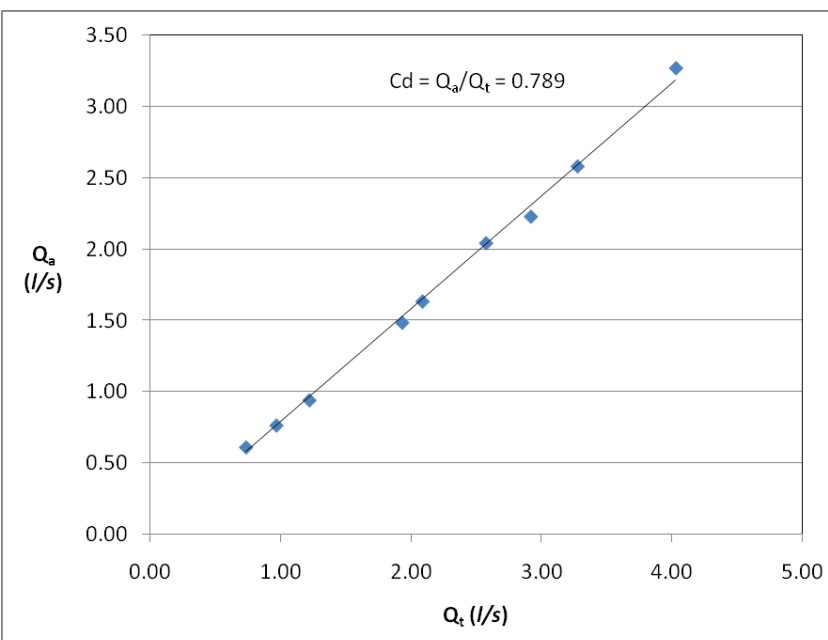

Fig. 5. Coefficient of discharge of ogee weir

Table- I: Coefficient of discharge of $W \downarrow$ and $W \uparrow$ models

\begin{tabular}{|c|c|c|c|c|c|c|}
\hline No. & $\begin{array}{c}\text { Head } \\
(\mathrm{m})\end{array}$ & $\begin{array}{c}Q_{t} \\
(1 / \mathrm{s})\end{array}$ & \multicolumn{2}{|c|}{$W \downarrow$ model } & \multicolumn{2}{|c|}{${ }^{\uparrow}$ model } \\
\cline { 4 - 7 } & & & $\begin{array}{c}Q_{a} \\
(1 / \mathrm{s})\end{array}$ & $C_{d}=Q_{d} / Q_{t}$ & $\begin{array}{c}Q_{a} \\
(1 / \mathrm{s})\end{array}$ & $C_{d}=Q_{d} / Q_{t}$ \\
\hline 1 & 0.010 & 3.662 & 1.114 & 0.304 & 1.089 & 0.297 \\
\hline 2 & 0.013 & 5.427 & 1.531 & 0.282 & 1.485 & 0.274 \\
\hline 3 & 0.015 & 6.727 & 1.815 & 0.270 & 1.750 & 0.260 \\
\hline 4 & 0.016 & 7.411 & 2.579 & 0.348 & 2.450 & 0.331 \\
\hline 5 & 0.019 & 9.590 & 2.883 & 0.301 & 2.816 & 0.294 \\
\hline 6 & 0.020 & 10.357 & 3.267 & 0.315 & 3.267 & 0.315 \\
\hline 7 & 0.021 & 11.143 & 3.500 & 0.314 & 3.770 & 0.338 \\
\hline 8 & 0.025 & 14.474 & 4.455 & 0.308 & 4.225 & 0.292 \\
\hline 9 & 0.030 & 19.027 & 6.126 & 0.322 & 5.445 & 0.286 \\
\hline
\end{tabular}

\begin{tabular}{|l|l|l|l|l|l|l|}
\hline & & & Mean & 0.307 & Mean & 0.299 \\
\hline
\end{tabular}

Table- II: Comparison of discharge among weirs

\begin{tabular}{|c|c|c|c|c|c|c|}
\hline No. & Head & Ogee & \multicolumn{2}{|c|}{$\downarrow$} & \multicolumn{2}{|c|}{ W } \\
\cline { 3 - 7 } & $(\mathrm{m})$ & $\begin{array}{c}Q_{a} \\
(1 / \mathrm{s})\end{array}$ & $\begin{array}{c}Q_{a} \\
(1 / \mathrm{s})\end{array}$ & $\begin{array}{c}\text { Increased } \\
\text { discharge } \\
(\%)\end{array}$ & $\begin{array}{c}Q_{a} \\
(1 / \mathrm{s})\end{array}$ & $\begin{array}{c}\text { Increased } \\
\text { discharge } \\
(\%)\end{array}$ \\
\hline 1 & 0.010 & 0.613 & 1.114 & 81.818 & 1.089 & 77.778 \\
\hline 2 & 0.013 & 0.766 & 1.531 & 100.000 & 1.485 & 93.939 \\
\hline 3 & 0.015 & 0.942 & 1.815 & 92.593 & 1.750 & 85.714 \\
\hline 4 & 0.016 & 1.485 & 2.579 & 73.684 & 2.450 & 65.000 \\
\hline 5 & 0.019 & 1.634 & 2.883 & 76.471 & 2.816 & 72.414 \\
\hline 6 & 0.020 & 2.042 & 3.267 & 60.000 & 3.267 & 60.000 \\
\hline 7 & 0.021 & 2.228 & 3.500 & 57.143 & 3.770 & 69.231 \\
\hline 8 & 0.025 & 2.579 & 4.455 & 72.727 & 4.225 & 63.793 \\
\hline 9 & 0.030 & 3.267 & 6.126 & 87.500 & 5.445 & 66.667 \\
\hline
\end{tabular}

\section{CONCLUSION}

A labyrinth weir model was prepared used in a tilting flume for comparing it with an ogee weir. The single labyrinth weir model was placed in the flume in two ways by flipping upstream and downstream sides. Compared to the ogee weir, the labyrinth weir provided greater discharges (table 2). Further while the coefficient of discharge of ogee weir is about 0.8 , the labyrinth weirs provided a value of about 0.3 .

\section{REFERENCES}

1. N. Hay, and G. Taylor, "Performance and design of labyrinth weirs", J. of Hydr. Engrg., ASCE, 96(11), 2337-2357,1970.

2. L. Darvas, "Discussion of performance and design of labyrinth weirs, by Hay and Taylor", J. of Hydr. Engrg., ASCE, 97(80), 1246-1251, 1971.

3. P. Tullis, N. Amanian, and D. Waldron, "Design of labyrinth weir spillways.” J.of Hydr. Engrg., ASCE, 121(3), 247-255, 1995.

4. B. Tullis, and J. Young, "Lake Brazos Dam model study of the existing spillway structure and a new labyrinth weir spillway structure." Hydraulics. Report No. 1575. Utah Water Research Laboratory. Logan, Utah, 2005.

5. K. Houston, "Hydraulic model study of Ute Dam labyrinth spillway." Report No. GR-82-7, U.S. Bureau of Reclamation, Denver, Colorado, 1982.

6. K. Houston, "Hydraulic model study of Hyrum Dam auxiliary labyrinth spillway." Report No. GR-82-13, U.S. Bureau of Reclamation, Denver, Colorado, 1983.

7. P. Tullis, "Standley Lake service spillway model study." Hydraulic Report No. 341, Utah Water Research Laboratory, Logan, Utah, 1993.

8. P. Tullis, "Weatherford Spillway model study." Hydraulic Report No 311, Utah Water Research Laboratory, Logan, Utah, 1992.

9. C. Willmore, "Hydraulic haracteristics of labyrinth weirs." M.S. report, Utah State University, Logan, Utah, 2004.

10.B.M. Crookston, Labyrinth weirs, Ph.D. thesis, Utah State University, Logan, Utah, 2010.

\section{AUTHORS PROFILE}

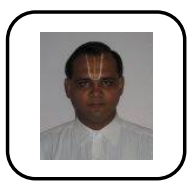

Dr. T.R. Neelakantan is a Senior Professor in Civil Engineering and Director - Accreditation and Ranking at Kalasalingam Academy of Research and Education, Tamilnadu, India. He obtained his Ph.D. degree in Civil Engineering from Anna University in the year 1998. His working experiences are from Anna University, IIT-Madras, SASTRA Deemed University and the University of Kentucky, Lexington, USA. He published more than 60 articles in reputed journals, and handled many government and private funded projects both in India and USA. 
D. Vijay was a B.Tech. Civil Engineering student (2015-2019) at Department of Civil Engineering, Kalasalingam Academy of Research and Education, Tamilnadu, India.

R. Sasikrishna was a B.Tech. Civil Engineering student (2015-2019) at Department of Civil Engineering, Kalasalingam Academy of Research and Education, Tamilnadu, India.

R. Ashokkumar was a B.Tech. Civil Engineering student (2015-2019) at Department of Civil Engineering, Kalasalingam Academy of Research and Education, Tamilnadu, India. 